\title{
HEREDO-DEGENERATIVE DISEASE
}

\section{GENETIC TESTING IN HUNTINGTON'S DISEASE}

The historical and clinical profiles of Huntington's disease (HD) presenting in 44 juveniles who were tested for CAG repeat expansions in the gene for HD were defined in a study reported by the US Huntington Disease Genetic Testing Group from the Hennepin County Medical Center, Minneapolis, MN. CAG repeat expansions were present in 33 and absent in 11 patients. All patients with CAG expansions had a positive family history of HD. Features of HD presenting in 12 children (having 80 or more CAG repeats) during the first decade included a family history of HD, usually in the father, and two or more of the following: declining school performance, seizures, oral motor dysfunction, rigidity, and gait disorder. Three young children with less CAG expansions had incomplete, atypical clinical profiles. More varied symptoms, usually behavioral and motor, occurred in HD presenting in the second decade. Patients not showing CAG expansions had atypical symptoms. Diagnostic genetic testing for HD in an at-risk child with incomplete or atypical symptoms or no paternal family history should be deferred pending longer follow-up and development of the characteristic profile. (Nance MA, and the US Huntington Disease Genetic Testing Group. Genetic testing of children at risk for Huntington's disease. Neurology Oct 1997;49:1048-1053). (Reprints: Dr Martha A Nance, Park Nicollet Clinic, 6490 Excelsior Blvd, Ste E500, St Louis Park, MN 55426).

COMMENT. The authors conclude that confirmation of a clinical diagnosis of Huntington's disease by CAG repeat analysis may be considered in a child under 10, provided the characteristic clinical profile of symptoms and positive family history are present, and the patient and family are aware of the relative medical and psychosocial risks and benefits of diagnostic gene testing. Caution and restraint are advised in cases with incomplete or atypical profiles.

Risk reversals in predictive testing for Huntington's disease are reported in a study of six patients at the Department of Medical Genetics, University of British Columbia, Vancouver, Canada. (Almqvist E, Adam S, Bloch $M$ et al. Am J Hum Genet Oct 1997;61:945-952). Three showed an increased risk on repeat direct testing for the HD mutation, and in three the risk was decreased. The importance of rigorous quality control to lessen likelihood of technological and human error is emphasized.

\section{MENTAL RETARDATION SYNDROMES}

\section{PERIVENTRICULAR HETEROTOPIA AND RETARDATION}

Three unrelated boys with a new multiple congenital anomaly-mental retardation syndrome are reported from the University of Minnesota Medical School, and the Universita Degli Studi di Pisa, Italy. Congenital abnormalities included 1) bilateral periventricular nodular heterotopia (BPNH) and ventriculomegaly, 2) cortical dysplasia, 3) cerebellar hypoplasia, 4) severe mental retardation, 5) epilepsy, 6) clinodactyly, 7) syndactyly, and 8) probable $\mathrm{X}$-linked inheritance. Involvement of the same Xq28 locus as found in classical, isolated BPNH was suggested. (Dobyns WB, Guerrini R, Czapansky-Beilman DK, et al. Bilateral periventricular nodular heterotopia with mental retardation and syndactyly in boys: a new X-linked mental retardation syndrome. 
Neurology Oct 1997;49:1042-1047). (Reprints: Dr William B Dobyns, Department of Neurology, Box 486 UMHC, 420 Delaware Street SE, Minneapolis, MN 55455).

COMMENT. In contrast to this new multiple congenital anomaly-mental retardation syndrome described by Dobyns et al, the classical BPNH syndrome of bilateral periventricular nodular heterotopia with epilepsy affects mainly girls with normal intelligence. One gene associated with classical BPNH is mapped to chromosome Xq28, similar to the finding in one case of Dobyns syndrome. Other syndromes associated with BPNH include: 1) BPNH with EhlerDanlos Syndrome, in females with normal intelligence; and 2) BPNH with frontonasal dysplasia, with nephrosis, the short-gut syndrome, and Vles agenesis of the corpus callosum syndrome, all affecting males with mental retardation, as in Dobyns syndrome. Most have X-linked inheritance patterns, and 3 are localized to Xq28. (see Sarnat HB, in Progress in Pediatric Neurology III 1997;pp365-369, for reference to X-linked periventricular heterotopia and markers in the distal Xq28 locus).

\section{OCULOCEREBROCUTANEOUS SYNDROME: SIGNS \& ETIOLOGIES}

Three additional cases, and a review of clinical features of a total of 26 cases of oculocerebrocutaneous (OCC) syndrome, are reported from Maastricht University, and University of Groningen, The Netherlands. Common features of OCC syndrome are 1) Ocular: orbital cysts, eyelid coloboma, microphthalmia/anophthalmia; 2) Cutaneous: skin appendages, dermal hypoplasia and punch-like defects; and 3) Cerebral: psychomotor retardation, seizures, dilated ventricles, cysts, callosal agenesis, and cerebellar hypoplasia. The probable pathogenic mechanism is a disruption of the anterior neuroectodermal plate resulting in neurocristopathy with craniofacial dysmorphism. Possible etiological hypotheses include a lethal mutation with survival by mosaicism, an autosomal dominant inheritance with high mutation rate, and exposure to a potential teratogen, as yet unrecognized. (Moog U, de Die-Smulders C, Systermans JMJ, Cobben JM. Oculocerebrocutaneous syndrome: report of three additional cases and aetiological considerations. Clin Genet October 1997;52:219-225). (Respond: Dr Ute Moog MD, Clinical Genetics Center Maastricht, PO Box 1475, 6201 BL Maastricht, The Netherlands).

COMMENT. The oculocerebrocutaneous syndrome, with its triad of clinical features, is frequently manifested by mental retardation and seizures. No familial cases have been reported. Encephalocraniocutaneous lipomatosis (ECCL) is also characterized by a triad of cutaneous, ocular and cerebral anomalies associated with retardation and seizures, and may be considered in the differential diagnosis. One patient described with OCC syndrome also showed lipomatosis of the spinal dura and a lipoma in the region of the zygoma. A mutation factor responsible for cell growth and cell migration has been proposed in the pathogenesis of ECCL, similar to that for hamartoses.

\section{MIGRAINE}

\section{DIVALPROEX CF. PROPANOLOL FOR MIGRAINE PROPHYLAXIS}

Migraine frequency was reduced in two-thirds of adult patients treated at the Allegheny Hdche Ctr, Pittsburgh, with either divalproex or propanolol cf to $19 \%$ with placebo. (Kaniecki RG. Arch Neurol Sept 1997;54:1141-1145). 